\title{
Work and Health, a Blind Spot in Curative Healthcare? A Pilot Study
}

\author{
Freek J. B. Lötters • Marleen Foets • \\ Alex Burdorf
}

Published online: 16 November 2010

(C) The Author(s) 2010. This article is published with open access at Springerlink.com

\begin{abstract}
Introduction Most workers with musculoskeletal disorders on sick leave often consult with regular health care before entering a specific work rehabilitation program. However, it remains unclear to what extent regular healthcare contributes to the timely return to work (RTW). Moreover, several studies have indicated that it might postpone RTW. There is a need to establish the influence of regular healthcare on RTW as outcome; "Does visiting a regular healthcare provider influence the duration of sickness absence and recurrent sick leave due to musculoskeletal disorders?". Methods A cohort of workers on sick leave for 2-6 weeks due to a-specific musculoskeletal disorders was followed for 12 months. The main outcomes for the present analysis were: duration of sickness absence till $100 \%$ return to work and recurrent sick leave after initial RTW. Cox regression analyses were conducted with visiting a general health practitioner, physical therapist, or medical specialist during the sick leave period as independent variables. Each regression model was adjusted for variables known to influence health care utilization like age, sex, diagnostic group, pain intensity, functional disability, general health perception, severity of complaints, job control, and physical load at work. Results Patients visiting a medical specialist reported higher pain intensity and more functional limitations and also had a worse health perception at start of the sick leave period compared with those not visiting a
\end{abstract}

F. J. B. Lötters $(\bowtie) \cdot$ M. Foets

Department of Health Economics, Institute of Health

Policy \& Management, Erasmus University, Rotterdam,

The Netherlands

e-mail: lotters@bmg.eur.nl

A. Burdorf

Department of Public Health, Erasmus MC, Rotterdam,

The Netherlands specialist. Visiting a medical specialist delayed return to work significantly ( $\mathrm{HR}=2.10 ; 95 \% \mathrm{CI} 1.43-3.07)$. After approximately 8 weeks on sick leave workers visiting a physical therapist returned to work faster than other workers. A recurrent episode of sick leave during the follow up quick was initiated by higher pain intensity and more functional limitations at the moment of fully return to work. Visiting a primary healthcare provider during the sickness absence period did not influence the occurrence of a new sick leave period. Conclusion Despite the adjustment for severity of the musculoskeletal disorder, visiting a medical specialist was associated with a delayed full return to work. More attention to the factor 'labor' in the regular healthcare is warranted, especially for those patients experiencing substantial functional limitations due to musculoskeletal disorders.

Keywords Return to work - Work disability - Health care services $\cdot$ Musculoskeletal disorders

\section{Introduction}

Musculoskeletal disorders (MSD) are well recognized as a major public health problem. Almost three quarters of the general Dutch population aged 25 years and over reported any musculoskeletal pain during the past 12 months of which low back pain (44\%) and neck shoulder pain (45\%) contributed the most [1]. These high prevalences lead to substantial direct costs, such as hospital care costs, general practice costs, and paramedical costs. These direct costs are estimated at $7.3 \%$ of the total healthcare costs in the Netherlands, thereby being one of the most expensive healthcare areas [2].

In addition, sick leave and productivity loss at work due to MSD lead to substantial indirect costs, which supersedes 
the direct costs, i.e. respectively 3.8 milliard Euro versus 303.6 million Euro as converted from the original estimates in 1995 [3]. For example, the indirect costs constituted $93 \%$ of the total costs of back pain [3, 4], whereas of the total cost for neck pain $77 \%$ was attributed to indirect costs [5]. In 2009, the overall sick leave in the Dutch working population was $4.2 \%$ (excluding sick leave due to pregnancy or absence shortly after giving birth) of which approximately one third was due to MSD [6]. Several studies have shown that productivity loss at work might precede future sick leave or might occur after full return to work (RTW) after an episode of sick leave [7, 8].

Adequate treatment that aims to reduce symptoms and functional limitations, with the ultimate goal early return to work seems therefore necessary. Most workers with musculoskeletal disorders will consult first with regular health care by visiting their general practitioner. The general practitioner may refer patients to a physical therapist or a medical specialist. When sick leave due to MSD occurs, the occupational physician is often involved after approximately 3 to 4 weeks. Hence, several physicians can be involved with the worker on sick leave due to MSD [9].

\section{Occupational Care Versus Regular Healthcare}

The care process of workers on sick leave in the Netherlands is quite unique. A 'sickness certificate' that exists in most other countries is not required, and the employer has to pay wages during sick leave for a period of maximum 2 years. Furthermore, in the Netherlands 'cure' (of complaints and symptoms) and 'supervision' (of functional rehabilitation and return to work) of workers on sick leave is strictly separated. In general, the regular healthcare professionals fulfill the care and cure component and occupational health services the supervision and control component.

In 2005 the Dutch Health Council noted that medical practice with regard to sick leave and work disability needed improvement [10]. One of the recommendations was to include the consequences of a health problem for labor participation into the guidelines for professionals in the regular healthcare. Several initiatives have been undertaken to increase the collaboration between general practitioners, medical specialists, and occupational physicians [11, 12]. However, until today this still seems difficult to establish and may even end up in delaying RTW [12]. Treatment advices towards the patient might be conflicting. Hence, it might be questionable whether the care workers on longterm sick leave receive is efficient and cost-efficient.

Specific interventions directed at RTW proved to be effective [13]. However, these interventions are often trajectories apart from regular healthcare. During these interventions workers may still be treated by their general practitioner, physical therapist or medical specialist. There is limited insight into the influence of regular healthcare use on RTW. Moreover, several studies have indicated that regular healthcare might postpone RTW [12, 14, 15]. Therefore, there is a need to assess the influence of regular healthcare on RTW as outcome.

In order to bridge the gap between occupational healthcare and regular healthcare, a better understanding of the influence of regular healthcare on RTW is essential. A better alignment between regular healthcare and occupational healthcare might eventually lead to a more efficient and cost-effective approach of treating the worker on sick leave with MSD with as ultimate goal a sustainable RTW.

The purpose of this study is to establish the healthcare utilization of workers on sick leave due to MSD. The principal question that will be addressed in this paper is: "Does visiting a regular healthcare provider influence duration of sickness absence and recurrent sick leave due to musculoskeletal disorders?"

\section{Methods}

\section{Subjects \& Study Design}

A longitudinal study with 12 months follow up was conducted, in which self-administered questionnaires were used at baseline, at full RTW, and at 12 months follow up.

Subjects were enrolled in the study by occupational health physicians during their consults or selected from the absenteeism register of a large Dutch occupational health service. For inclusion into the study a subject had to be on sick leave due to non-specific musculoskeletal disorders for 2 to 6 weeks, as registered by the occupational physician using the CAS code system [16]. Based on the initial diagnosis by the occupational physician, subjects had to fill in a diagnosis specific questionnaire (i.e. low back, hip, knee, ankle/foot, neck/shoulder, or wrist/hand/elbow). Subjects were excluded when they suffered from specific underlying pathology, such as a fractured leg or discus prolaps. After signing an informed consent, subjects received the questionnaire. Nonresponders received a reminder after 2 weeks and a second reminder with a questionnaire after 3 weeks. The first date of sick leave and the RTW-date were obtained from the medical records of the occupational health service. RTW was defined as a full return to the original job, i.e. with the same workhours as before the sick leave. A second questionnaire was administered within 2 weeks after return to work, with similar procedures for reminders.

Contents of the Questionnaires

In both the baseline and RTW questionnaire information was obtained on personal factors, work related factors, 
nature and severity of the musculoskeletal disorders, functional limitations, and general health perceptions. In the RTW questionnaire additional questions were asked on healthcare utilization during the sickness absence period. In this paper we will address only those variables that were relevant for answering the question raised in the introduction. Variables were used that are known to relate to healthcare utilization and that describe the severity of MSD $[17,18]$. A more comprehensive description of the complete study can be found in a previous paper [19].

We used a modified Nordic Questionnaire to assess the nature and severity of the complaints [20], and a 10 point numerical rating scale to determine the level of perceived pain. Pain intensity was measured for the body part that represented the initial sick leave diagnosis. From the Nordic Questionnaire, the severity of complaints was defined when more than three symptoms concerning the initial diagnosis were presented (i.e. pain, local muscle fatigue, cramp, numbness, radicular tingling, loss of strength, movement reduction, or swelling).

The functional limitations caused by the complaints were assessed by the Roland Morris Disability Questionnaire for back complaints [21] and comparable questionnaires for other body locations. For the latter purpose we changed the addition "cause of my back' into "cause of my neck', 'cause of my knee' etc. Furthermore, for neck, shoulder, and elbow/wrist/ hand complaints 6 items concerning walking and standing were substituted by corresponding items from the Sickness Impact Profile concerning disability due to upper extremity disorders [22]. The Sickness Impact Profile is a general health questionnaire, which formed the basis for the Roland-Morris Disability Questionnaire for low back pain.

Finally, general health perceptions were measured by the thermometer (EQ-VAS) that is incorporated in the Euroqol-5d [23]. On a scale of 0-100 subjects were asked to appraise their present health status.

Information about healthcare utilization was obtained by asking the participant whether he had visited a general practitioner, therapist, or medical specialist during the sickness absence period. The category therapist consisted of physical therapist, manual therapist, mensendieck /cesar therapist or another therapist. The category medical specialist combined orthopedist, neurologist, surgeon, and other medical specialist. Perceived physical workload was measured by using a 10-point numerical rating scale [24]. For the psychosocial factors at work the Job Content Questionnaire was used [25]. Within this questionnaire three aspects are distinguished: work demands, skill discretion, and decision latitude. A four-point scale was used for each item, and subsequently, a sum score for each aspect was calculated. The variables skill discretion and decision latitude were combined in one dichotomous variable indicating 'job control'.

Recurrent sick leave during the follow-up was defined as at least one new episode of sickness absence of minimal 7 days due to the initial MSD. This was measured by means of questions on the frequency and duration of sick leave. These questions were derived from a questionnaire with high specificity and sensitivity for sickness absence due to back pain [26].

\section{Data Analysis}

We used Cox Proportional Hazard (PH) regression to determine the effect of healthcare utilization on the duration of sickness absence. The required assumption that the hazard ratio is constant over time was checked graphically. Since subjects were considered not at risk in the period between first day of sick leave and day of filling in the questionnaire, this lag time was subtracted from the total sick leave. Subjects were right censored when they did not RTW after 12 months of follow-up. For the analysis these subjects were assigned to have a sickness absence period of 365 days. Four models were calculated: consultation of a general health practitioner, a therapist, a medical specialist, and the combination of physical therapist or medical specialist. All models were controlled for age, sex, diagnose group, severity of complaints, pain intensity, functional limitations, general health perception, physical workload, and job control measured at baseline. All variables were entered in the subsequent models simultaneously.

The influence of healthcare utilization on a recurrent sick leave episode during the follow up was calculated with logistic regression analysis. We used the same strategy as described by the Cox PH regression analyses. However, measures for pain intensity, functional limitations and general health perception were now taken form the second questionnaire (administered shortly after RTW). The presence of recurrent sick leave was retrieved from the third questionnaire at 12 months follow up.

\section{Results}

Study Population and Characteristics

For the analysis presented in this paper we used a sample of 252 workers of which 232 returned to work fully within 365 days of follow up [19]. In Table 1 the basic characteristics of the study population are presented. Most subjects were male (70\%) and a-specific low back pain was the most common MSD. 
Table 1 Population characteristics and health profile, measured at baseline $(n=252)$

\begin{tabular}{lcc}
\hline & Mean (SD) & Percentage (\%) \\
\hline Age & $42.6(9.3)$ & 70.0 \\
Sex (man) & \\
Diagnostic group: & 51.2 \\
$\quad$-Low back pain & 48.8 \\
$\quad$-Other MSD & \\
$\begin{array}{l}\text { Severity of complaints: } \\
\text { More than 3 symptoms }\end{array}$ & \\
$\begin{array}{l}\text { Perceived pain (0-10) } \\
\text { Perceived functional } \\
\text { limitations (0-24) }\end{array}$ & $6.4(1.9)$ \\
$\begin{array}{l}\text { Perceived general health } \\
\quad(0-100)\end{array}$ & $58.2(19.0)$ & \\
$\begin{array}{l}\text { Good job control (y/n) } \\
\text { Perceived physical } \\
\text { workload (0-10) }\end{array}$ & \\
\hline
\end{tabular}

Sickness Absence Duration and Recurrent Sick Leave

Of the 232 subjects that returned to work during the 12 months follow up the mean sickness absence duration was 111 days. Taking into account the subjects that were still on sick leave after 12 months follow up $(n=20(8 \%))$ the sickness absence duration was 131 days (Table 2).

Of the workers that returned to work fully $(n=232)$ $25 \%$ reported a new episode of sick leave in the follow up period. The median duration of the follow up period was 278 days. The recurrence rate of sickness absence due to MSD (expressed in person days, i.e. total days of follow up of all workers) was 0.09 per 100 person days, implying a recurrence rate of $29 \%$ over 365 days follow up.

\section{Health Status and Healthcare Utilization}

In Table 3 the healthcare utilization during sick leave is described. Most subjects visited a general practitioner for their musculoskeletal problem. More than 4 out of 5 subjects concomitantly visited a therapist. In $80 \%$ of the cases this was a physical therapist. Two out of five also visited a medical specialist.

Table 4 shows the health status of the subjects at baseline and the healthcare utilization during the sickness absence period. Pain intensity, functional limitations and
Table 3 Healthcare utilization during sick leave period

\begin{tabular}{ll}
\hline $\begin{array}{l}\text { Healthcare provider (number } \\
\text { of subjects that answered } \\
\text { the question) }\end{array}$ & $\begin{array}{l}\text { Percentage of } \\
\text { subjects that visited } \\
\text { healthcare provider }(\%)\end{array}$ \\
\hline $\begin{array}{l}\text { General practitioner }(n=202) \\
\text { Therapist }(n=196)\end{array}$ & 90.6 \\
-Physical therapist & 82.7 \\
Medical specialist $(n=170)$ & $80.2^{\#}$ \\
$\#$ Of the 196 subjects that visited a therapist
\end{tabular}

general health perception did not differ between workers visiting a general practitioner and those that did not. For subjects visiting a therapist their general health perception was significantly worse. For workers visiting a medical specialist during sick leave pain intensity, functional limitations, and perceived health were significantly worse than those not visiting a medical specialist (pain intensity: $F=5.4, \quad P=0.02 ;$ functional limitations: $F=8.1$, $P=0.005$; and general health: $F=4.7, P=0.03$ ).

Table 5 shows the results of the logistic regression analyses with respectively consulting a general practitioner, a therapist, and a medical specialist as dependent variables. These results clearly illustrate that older workers, with more severe complaints and more functional limitations visited a medical specialist more than other workers. In the multivariate analysis the healthcare status at the beginning of the sick leave period did not influence the consultation of a therapist.

\section{Regular Healthcare and Duration of Sickness Absence}

In Table 6 the results of four Cox regression models are presented for visiting a general practitioner, a therapist, a medical specialist, or a combination of therapist and medical specialist. All models were adjusted for demographic factors, health related factors, and work-related factors. Visiting a general practitioner did not influence the duration of sickness absence (model 1). Visiting another therapist than a physical therapist showed a two fold risk for longer sickness absence, compared with not visiting a therapist at all (model 2). Visiting a medical specialist raised the odds for longer sickness absence duration twofold (model 3). Figure 1 shows the survival curve of model 3 . To get an indication of the reduction in hazard rate after

Table 2 Sickness absence duration

\begin{tabular}{llll}
\hline & $\begin{array}{l}\text { Number of } \\
\text { subjects }(\% \text { total) }\end{array}$ & $\begin{array}{l}\text { Sickness absence } \\
\text { duration in days (mean (SD)) }\end{array}$ & $\begin{array}{l}\text { Sickness absence } \\
\text { duration in days (median) }\end{array}$ \\
\hline $\begin{array}{l}\text { All subjects including right sensored } \\
\text { Subjects that returned to work fully }\end{array}$ & $252(100 \%)$ & $131(99)$ & 97 \\
\end{tabular}


Table 4 Health status and healthcare utilization (general practitioner, therapist or medical specialist)

\begin{tabular}{|c|c|c|c|c|}
\hline Healthcare provider & $\begin{array}{l}\text { Visited } \\
(\mathrm{y} / \mathrm{n})\end{array}$ & $\begin{array}{l}\text { Pain intensity } \\
(0-10) \\
\text { Mean (SD) }\end{array}$ & $\begin{array}{l}\text { Functional limitations } \\
(0-24) \\
\text { Mean (SD) }\end{array}$ & $\begin{array}{l}\text { General health } \\
(0-100) \\
\text { Mean }(\mathrm{SD})\end{array}$ \\
\hline \multirow[t]{2}{*}{ General practitioner } & Yes & $6.2(2.0)$ & $12.4(5.0)$ & $58.4(18.4)$ \\
\hline & No & $6.8(1.3)$ & $10.5(4.2)$ & $64.8(16.1)$ \\
\hline \multirow[t]{2}{*}{ Therapist } & Yes & $6.3(1.9)$ & $12.3(4.9)$ & $57.7(18.2)$ \\
\hline & No & $6.1(2.2)$ & $11.5(4.8)$ & $64.9(18.1)^{\#}$ \\
\hline \multirow[t]{2}{*}{ Medical specialist } & Yes & $6.7(1.9)^{\#}$ & $13.2(4.6)^{\#}$ & $56.1(18.8)^{\#}$ \\
\hline & No & $5.9(2.1)$ & $11.1(4.8)$ & $62.1(17.2)$ \\
\hline
\end{tabular}

\# $P \leq 0.05$

Table 5 Effect of health care status on healthcare utilization (results of multivariate analyses)

\begin{tabular}{lllr}
\hline Variables in the model & $\begin{array}{l}\text { Model 1 } \\
\text { General practitioner } \\
\text { OR (95\% CI) }\end{array}$ & $\begin{array}{l}\text { Model 2 } \\
\text { Therapist } \\
\text { OR (95\% CI) }\end{array}$ & $\begin{array}{l}\text { Model 3 } \\
\text { Medical specialist } \\
\text { OR (95\% CI) }\end{array}$ \\
\hline Age & $0.96(0.91-1.02)$ & $1.02(0.97-1.07)$ & $1.05(1.01-1.09)^{\mathrm{b}}$ \\
Sex (male) & $1.51(0.52-4.37)$ & $0.48(0.18-1.29)$ & $0.72(0.34-1.54)$ \\
Diagnostic group (LBP) & $3.05(0.87-10.69)^{\mathrm{a}}$ & $1.14(0.47-2.74)$ & $1.83(0.86-3.87)$ \\
Severity of complaints & $0.98(0.30-3.26)$ & $1.91(0.76-4.81)$ & $2.01(0.96-4.19)^{\mathrm{a}}$ \\
Pain intensity & $0.74(0.53-1.04)^{\mathrm{a}}$ & $0.99(0.79-1.23)$ & $1.10(0.91-1.32)$ \\
Functional limitations & $1.10(0.95-1.27)$ & $1.00(0.91-1.10)$ & $1.09(1.01-1.19)^{\mathrm{b}}$ \\
General health & $0.98(0.95-1.01)$ & $0.98(0.95-1.00)^{\mathrm{a}}$ & $0.99(0.97-1.01)$ \\
\hline
\end{tabular}

a $P \leq 0.10 ;{ }^{\mathrm{b}} P \leq 0.05 ; \mathrm{OR}>1$ indicates a higher risk for visiting the healthcare provider

Table 6 The effect of healthcare utilization on duration of sickness absence (results of multivariate analysis)

\begin{tabular}{|c|c|c|c|c|}
\hline Variables in the model & $\begin{array}{l}\text { Model } 1 \\
\text { HR (95\% CI) }\end{array}$ & $\begin{array}{l}\text { Model } 2 \\
\text { HR }(95 \% \text { CI) }\end{array}$ & $\begin{array}{l}\text { Model } 3 \\
\text { HR (95\% CI) }\end{array}$ & $\begin{array}{l}\text { Model } 4 \\
\text { HR }(95 \% \text { CI) }\end{array}$ \\
\hline General practitioner & $1.35(0.79-2.30)$ & - & & - \\
\hline \multicolumn{5}{|l|}{ Therapist: } \\
\hline Physical therapist & - & $1.28(0.84-1.96)$ & - & $0.75(0.49-1.12)$ \\
\hline Other & - & $2.17(1.27-3.70)^{\mathrm{c}}$ & - & - \\
\hline None & - & 1 & - & - \\
\hline Medical specialist & - & - & $2.10(1.43-3.07)^{\mathrm{d}}$ & $1.82(1.02-3.27)^{\mathrm{b}}$ \\
\hline Medical specialist or physical therapist & - & - & - & $1.73(1.07-2.79)^{\mathrm{b}}$ \\
\hline Age & $0.99(0.97-1.01)$ & $0.99(0.97-1.01)$ & $0.98(0.97-1.00)^{\mathrm{a}}$ & $0.98(0.96-1.00)^{\mathrm{b}}$ \\
\hline Sex (male) & $0.77(0.55-1.09)$ & $0.76(0.54-1.07)$ & $0.58(0.40-0.85)^{\mathrm{b}}$ & $0.67(0.47-0.95)^{\mathrm{b}}$ \\
\hline Diagnostic group (LBP) & $0.65(0.45-0.92)^{\mathrm{c}}$ & $0.69(0.48-0.97)^{\mathrm{b}}$ & $0.73(0.50-1.06)^{\mathrm{a}}$ & $0.67(0.47-0.96)^{\mathrm{b}}$ \\
\hline Severity of complaints & $1.48(1.05-2.08)^{\mathrm{b}}$ & $1.33(0.94-1.89)^{\mathrm{a}}$ & $1.31(0.89-1.93)$ & $1.21(0.85-1.72)$ \\
\hline Pain intensity & $1.04(0.95-1.14)$ & $1.04(0.95-1.14)$ & $1.03(0.94-1.14)$ & $1.04(0.95-1.14)$ \\
\hline Functional limitations & $1.01(0.97-1.05)$ & $1.01(0.97-1.04)$ & $1.01(0.97-1.05)$ & $1.01(0.96-1.04)$ \\
\hline General health & $1.00(0.99-1.01)$ & $0.99(0.99-1.00)$ & $0.99(0.98-1.00)$ & $0.99(0.98-1.00)$ \\
\hline Physical work load & $1.03(0.95-1.11)$ & $1.01(0.93-1.09)$ & $1.09(1.01-1.18)^{\mathrm{b}}$ & $1.06(0.98-1.15)$ \\
\hline Job control & $0.97(0.71-1.31)$ & $1.06(0.77-1.46)$ & $0.96(0.68-1.35)$ & $0.94(0.67-1.31)$ \\
\hline
\end{tabular}

${ }^{\mathrm{a}} P \leq 0.10 ;{ }^{\mathrm{b}} P \leq 0.05 ;{ }^{\mathrm{c}} P \leq 0.01 ;{ }^{\mathrm{d}} P \leq 0.001 ; \mathrm{HR}>1$ indicates a higher risk for prolonged duration of sickness absence; The models were adjusted for age, sex, diagnosis group, pain intensity, functional disability, general health perception, severity of complaints, job control and physical workload 


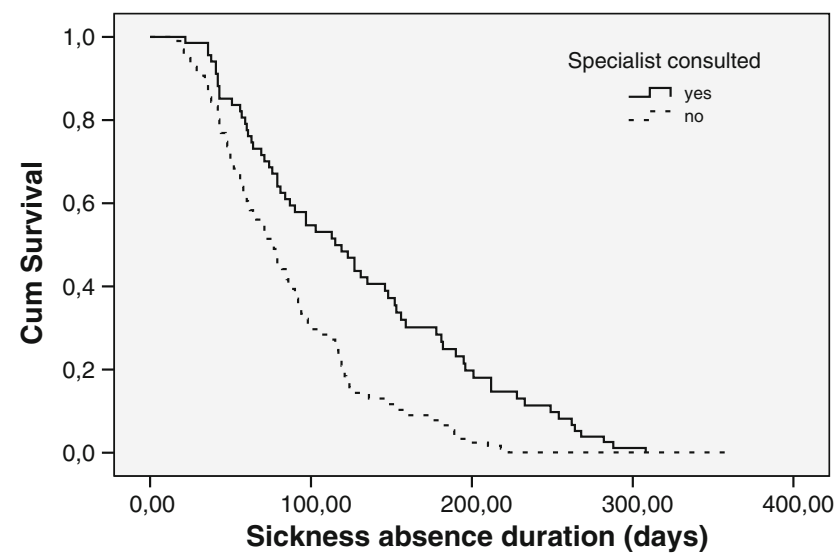

Fig. 1 Survival function at mean of covariates for Model 3 (see Table 6)

including the control variables, we also performed an analysis on model 3 without the pain, disability and general health variables. Including these health variables induced a reduction in hazard rate for prolonged sickness absence by visiting a specialist by $10 \%$. (HR $(95 \% \mathrm{CI})$ [specialist $]=2.30(1.60-3.31)$ ).

It often occurs that besides visiting a medical specialist a subject concomitantly visits a physical therapist in case of musculoskeletal problems. Hence, we performed an additional analysis on health status on those visiting a medical therapist, a physical therapist, or both. The 4th model in which medical specialist and physical therapist are combined showed that visiting a medical specialist whether or not combined with a visiting a physical therapist ends up in lengthening of the sickness absence period (model 4). After approximately 8 weeks workers who visited a physical therapist returned to work more quickly than the other groups (model 4; Fig. 2). Additional analysis showed a significant difference of 42.5 days between those visiting a physical therapist and those visiting a specialist or both physical therapist and medical specialist.

Figure 1 presents the survival function for model 1 at the mean of the covariates mentioned in Table 1. Figure 2 presents the survival function for model 4 . The latter figure shows that visiting only a physical therapist, although not statistically significant, tends to accelerate RTW after approximately 8 weeks of sick leave, whereas visiting both a physical therapist and medical specialist or only medical specialist postponed RTW.

\section{Regular Healthcare and Recurrent Sick Leave}

In the logistic regression models no relation of healthcare utilization with recurrent sick leave was found. However, workers with high pain intensity had a $30 \%$ more chance on recurrent sick leave than those with no or less pain,

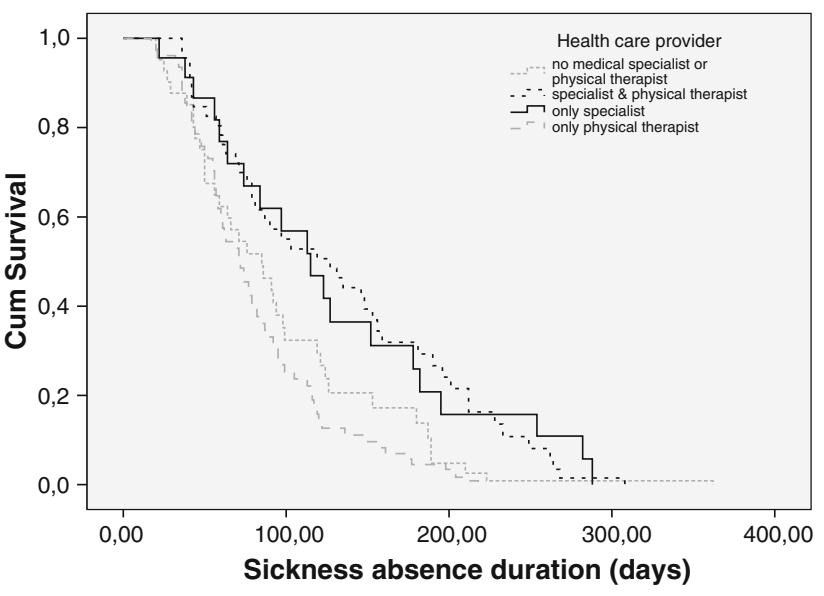

Fig. 2 Survival function at mean of covariates for Model 4 (see Table 6)

whereas workers with more functional limitations showed a $10 \%$ greater chance on a recurrent sick leave.

\section{Discussion}

In this study we investigated whether visiting a healthcare provider (general practitioner, therapist and/ or medical specialist) influenced the duration of sickness absence in workers already on sick leave for 2-6 weeks due to musculoskeletal disorders. Workers visiting a medical specialist showed more pain, more functional limitations, and worse health perceptions. After controlling for these variables, visiting a medical specialist clearly postponed RTW. Visiting a general practitioner or a physical therapist did not influence the duration of sickness absence significantly. However, after approximately 8 weeks of sick leave workers visiting only a physical therapist tended to RTW more quickly than those visiting only a medical specialist or medical specialist and physical therapist.

Visiting a healthcare provider during the sick leave period did not influence the occurrence of a subsequent new sick leave episode. Pain intensity and functional limitations were significant determinants of a recurrent sick leave period. In a previous study we also found that workers with relapse of work absence had poorer levels of health at time of return to work [27]. This is in accordance with findings in other studies [17, 28].

It has to be noted that comparison of the results in the present study is hampered due to the few available studies on regular healthcare with work resumption as primary outcome. Moreover, the Dutch healthcare system differs from other systems, which hampers comparison with studies from other countries. Hence, we will first discuss our findings in the light of the Dutch situation and subsequently will put them in international perspective where possible. 


\section{Care Seeking}

In our study more than $90 \%$ of the subjects sought care for musculoskeletal complaints at their general practitioner. Other studies found percentages between 25-44\% [17, 29, 30] for care seeking for either low back pain or neckshoulder pain. At the time of the present study, within the Dutch system, patients with (musculoskeletal) health problems would first visit their general practitioner. The general practitioner either treated patients himself or referred patients to a physical therapist or a medical specialist. In our study workers were at least 2 weeks on sick leave due to musculoskeletal disorders. It is reasonable to assume that most of them had visited their general practitioner, which explains the higher prevalence of general practitioner visits in our study. This is in accordance with a Canadian study among hospital workers. They found that those workers with a claim for a work-related musculoskeletal disorder showed a much higher healthcare utilization than those without a claim [31].

In our study worse health conditions resulted in more consultation of the medical specialist. This is in accordance with earlier findings in studies on neck/ shoulder pain and back pain [17, 29, 30]. In these studies more intense pain and functional limitations strongly determined healthcare utilization.

Each Dutch company is obliged to offer his employees access to occupational healthcare, often initiated by an occupational physician. A worker on sick leave has direct access to an occupational physician, without having to have a permit of his/ her general practitioner. In our study $52 \%$ of the subjects were enrolled by their occupational physician and $48 \%$ by the sick leave registration of the occupational health service [27]. Although not measured directly (due to study design constraints), it can be assumed that most workers entered via the $\mathrm{OHC}$ administration also must have visited their occupational physician.

\section{General Practitioner}

Despite the recent attention for 'labor' in Dutch clinical guidelines, resumption to work is not a standard topic of conversation during consultation of patients on sick leave due to musculoskeletal complaints [32]. Our study showed a modest, non-significant effect of a GP visit on prolonged sickness absence $(\mathrm{HR}=1.35)$.

\section{Medical Specialist}

Our finding that consulting a medical specialist postponed RTW is confirmed by other studies. Steenstra et al. showed that in a group of Dutch healthcare professionals visiting a medical specialist significantly increased the duration of sickness absence [33]. In a previous study we found that visiting a medical specialist 12 months prior to inclusion in the study raised the risk for a longer sickness absence duration [19]. In a study on the role of disability management by physicians on RTW the occupational physician stated that the medical specialists sometimes were an obstacle in the process of RTW [14]. In a study among scaffolders on sick leave for at least 30 days, being treated by a medical specialist increased the risk for prolonged sickness absence four times [34].

It has been mentioned in (patient) focus groups that more attention by the physician for the patient could be interpreted by the patient as an affirmation of the importance of his/ her problem, thereby inducing prolonged sick leave. In contrast, the realization of a patient that the physician will not take charge of his/her problem seems an incitement for RTW [35]. In this respect a better focus of medical specialist on work-related problems might prompt more accurate communication (with the patient and other healthcare providers involved) about these problems, resulting in an earlier RTW [36].

\section{Physical Therapy}

We found no difference on sickness absence duration between those visiting a physical therapy and those that did not. Although we have no insight in the applied treatment modalities, we assume that exercise therapy will be applied in accordance with well-accepted established guidelines within physical therapy [37]. Our finding is in accordance with other studies that found no effect of exercise therapy on absenteeism outcomes, i.e. also no increase in sickness absence duration [38]. A recent study by Reme et al. [15] showed that having been to a physical therapist prior to inclusion in the trial was a risk factor for long-term sick leave. In a review by Hayden et al. [39] exercise therapy appears to be slightly effective in decreasing pain and improving function in adults with chronic low back pain. The role of exercise therapy on the outcome of sickness absence still remains unclear [38, 39]. However, in their review, Hayden et al indicated some evidence that a graded activity program improved absenteeism outcomes. Schaafsma et al. [38] suggested that workplace involvement besides exercise therapy might be positive on the outcome of RTW. Recent studies indeed showed that the combination of graded activity provided by physical therapists in combination with a workplace improvement decreased sickness absence duration substantially [40]. Our data showed a trend after 8 weeks that visiting a physical therapist might induce earlier RTW, not necessarily by giving 'graded activity' training, but focusing on improving functional performance in daily activities including work according to Dutch quidelines [37]. 
Limitations of the Study

Evaluating treatment effects from observational data can be problematic. Prognostic factors may influence treatment decisions, producing a type of bias referred to as "confounding by indication". Controlling for known prognostic factors may reduce this problem, but it remains always possible that an unknown factor influences the prognosis or that there is complex interaction of factors. The results of this study showed that functional limitations were important for consulting a medical specialist. Thus, it might be expected that functional limitations also will contribute to the duration of sickness absence. However, after adjustment for functional limitations the effect of medical specialist on sickness absence reduced by about $10 \%$. Hence, this indicates that visiting a medical specialist is largely responsible for the observed prolonged RTW.

A way to overcome the problem of 'confounding by indication' is the application of a propensity score based on relevant confounding factors. However, using propensity scores requires a relatively large population, due to the necessary matching or stratifying of the data [41]. In our study we controlled for severity of complaints, level of functional impairment, and general health perception by including these in the statistical analyses as co-variates. Due to the sample constraints, we were not able to calculate a propensity score. However, additional analyses showed that when stratified in low functional limitations and high functional limitations the prolonging effect of consultation of a medical specialist on duration of sickness absence remained very similar. The same model showed a tendency though that after approximately 3.5 months of sickness absence, workers with high functional limitations returned to work slower than those with less functional limitations.

In this study we measured the prevalence of healthcare utilization and not the content of the treatment delivered by the healthcare providers. Moreover, the primary outcome of consideration was sickness absence duration. Thus, the results presented in this study do not give any indication of the effectiveness of the treatments on outcomes such as pain intensity and functional limitations.

\section{Future Challenges}

As already stated, only mentioning the topic of labor in medical guidelines is not sufficient to treat and guide workrelated (musculoskeletal) health problems (like sickness absence and work disability) adequately. Important in this respect are also the structure and organization of healthcare. For example, in the Netherlands no 'sickness certificate' is required, whereas in most other countries this is compulsory. The impact of the necessity to acquire a 'sickness certificate' on the subsequent treatment trajectory for workers on sick leave and timely work resumption is not known. A longitudinal study with international perspective (i.e. across different social benefit systems and health care systems) gives the opportunity to take into account system variables such as the infrastructure of regular healthcare and the concomitant (social) legislation around work disability. In order to improve the regular medical practice around sick leave and work disability one should first determine the systematic barriers, due to infrastructure of health care and the concomitant rules and regulations.

\section{Conclusions}

Despite the adjustment for the severity of the musculoskeletal disorder, visiting a medical specialist postponed fully return to work. More attention to the factor 'labor' in regular healthcare provision is necessary, especially for those patients experiencing functional limitations due to musculoskeletal disorders.

Open Access This article is distributed under the terms of the Creative Commons Attribution Noncommercial License which permits any noncommercial use, distribution, and reproduction in any medium, provided the original author(s) and source are credited.

\section{References}

1. Picavet HS, Schouten JS. Musculoskeletal pain in the netherlands: prevalences, consequences and risk groups, the DMC(3)study. Pain. 2003;102(1-2):167-78.

2. Meerding WJ, Bonneux L, Polder JJ, Koopmanschap MA, van der Maas PJ. Demographic and epidemiological determinants of healthcare costs in netherlands: cost of illness study. BMJ. 1998; 317(7151):111-5.

3. van Tulder MW, Koes BW, Bouter LM. A cost-of-illness study of back pain in the Netherlands. Pain. 1995;62(2):233-40.

4. Hutubessy RC, van Tulder MW, Vondeling H, Bouter LM. Indirect costs of back pain in the netherlands: a comparison of the human capital method with the friction cost method. Pain. 1999; 80(1-2):201-7.

5. Borghouts JA, Koes BW, Vondeling H, Bouter LM. Cost-ofillness of neck pain in the Netherlands in 1996. Pain. 1999;80(3): 629-36.

6. Ziekteverzuimpercentage nederland [homepage on the Internet]. Voorburg: centraal Bureau voor Statistiek (2009). Available from: www.statline.cbs.nl.

7. Bergstrom G, Bodin L, Hagberg J, Aronsson G, Josephson M. Sickness presenteeism today, sickness absenteeism tomorrow? A prospective study on sickness presenteeism and future sickness absenteeism. J Occup Environ Med. 2009;51(6):629-38.

8. Lötters F, Meerding WJ, Burdorf A. Reduced productivity after sickness absence due to musculoskeletal disorders and its relation to health outcomes. Scand J Work Environ Health. 2005;31(5): $367-74$. 
9. IJzelenberg W, Burdorf A. Patterns of care for low back pain in a working population. Spine. 2004;29(12):1362-8.

10. Gezondheidsraad. Beoordelen, behandelen en begeleiden. medisch handelen bij ziekteverzuim en arbeidsongeschiktheid. Den Haag: Gezondheidsraad; 2005.

11. de Buck PD, van Amstel RJ, Buijs PC, Maasen JH, van Dijk FJ, Hazes JM, et al. Communication between Dutch rheumatologists and occupational physicians in the occupational rehabilitation of patients with rheumatic diseases. Ann Rheum Dis. 2002;61(1): $62-5$.

12. Faber E, Bierma-Zeinstra SM, Burdorf A, Nauta AP, Hulshof CT, Overzier PM, et al. In a controlled trial training general practitioners and occupational physicians to collaborate did not influence sickleave of patients with low back pain. J Clin Epidemiol. 2005;58(1):75-82.

13. Franche RL, Cullen K, Clarke J, Irvin E, Sinclair S, Frank J, et al. Workplace-based return-to-work interventions: a systematic review of the quantitative literature. J Occup Rehabil. 2005; 15(4):607-31.

14. Anema JR, Van Der Giezen AM, Buijs PC, Van Mechelen W. Ineffective disability management by doctors is an obstacle for return-to-work: a cohort study on low back pain patients sicklisted for 3-4 months. Occup Environ Med. 2002;59(11):729-33.

15. Reme SE, Hagen EM, Eriksen HR. Expectations, perceptions, and physiotherapy predict prolonged sick leave in subacute low back pain. BMC Musculoskelet Disord. 2009;10:139.

16. LISV. CAS: Classificaties voor arbo en SV. Utrecht: Voorlichtingscentrum Sociale Verzekering; 1997.

17. IJzelenberg W, Burdorf A. Risk factors for musculoskeletal symptoms and ensuing health care use and sick leave. Spine. 2005; 30(13):1550-6.

18. Mortimer M, Ahlberg G, MUSIC-Norrtalje Study Group. To seek or not to seek? Care-seeking behaviour among people with lowback pain. Scand J Public Health. 2003;31(3):194-203.

19. Lötters F, Burdorf A. Prognostic factors for duration of sickness absence due to musculoskeletal disorders. Clin J Pain. 2006; 22(2):212-21.

20. Kuorinka I, Jonsson B, Kilbom A, Biering-Sorensen F, Andersson G, Jorgensen K. Standardised nordic questionnaires for the analysis of musculoskeletal symptoms. Appl Ergon. 1987;18(3): 233-7.

21. Roland M, Morris R. A study of the natural history of back pain. part I: development of a reliable and sensitive measure of disability in low-back pain. Spine. 1983;8:141-4.

22. Bergner M, Bobbitt RA, Carter WB, Gilson BS. The sickness impact profile: development and final revision of a health status measure. Med Care. 1981;19:787-805.

23. Group E. EuroQol: a new facility for the measurement of healthrelated quality of life. Health Policy. 1990;16:199-208.

24. Hazard RG, Haugh LD, Reid S, Preble JB, MacDonald L. Early prediction of chronic disability after occupational low back injury. Spine. 1996;21:945-51.

25. Karasek R, Brisson C, Kawakami N, Houtman I, Bongers P, Amick B. The job content questionnaire (JCQ): an instrument for internationally comparative assessments of psychosocial job characteristics. J Occup Health Psychol. 1998;3(4):322-55.

26. Burdorf A, Post W, Bruggeling T. Reliability of a questionnaire on sickness absence with specific attention to absence due to back pain and respiratory complaints. Occup Environ Med. 1996;53(1): $58-62$.

27. Lötters F, Hogg-Johnson S, Burdorf A. Health status, its perceptions, and effect on return to work and recurrent sick leave. Spine. 2005;30(9):1086-92.

28. Carey TS, Garrett JM, Jackman A, Hadler N. Recurrence and care seeking after acute back pain: Results of a long-term follow-up study. north carolina back pain project. Med Care. 1999;37(2): 157-64.

29. Cote P, Cassidy JD, Carroll L. The treatment of neck and low back pain: who seeks care? who goes where? Med Care. 2001; 39(9):956-67.

30. Grooten WJ, MUSIC Norrtalje Study Group. Predictors for persistent neck/shoulder pain, medical care-seeking due to neck/ shoulder pain and sickness absence. Clin Rehabil. 2007;21(7): 648-59.

31. Koehoorn M, Cole DC, Hertzman C, Lee H. Health care use associated with work-related musculoskeletal disorders among hospital workers. J Occup Rehabil. 2006;16(3):411-24.

32. Weevers HJ, van der Beek AJ, van den Brink-Muinen A, Bensing $\mathrm{J}$, Boot CR, van Mechelen W. Communication about work between general practitioners and patients consulting for musculoskeletal disorders. Qual Prim Care. 2009;17(3):197-203.

33. Steenstra IA, Koopman FS, Knol DL, Kat E, Bongers PM, de Vet $\mathrm{HC}$, et al. Prognostic factors for duration of sick leave due to lowback pain in Dutch health care professionals. J Occup Rehabil. 2005;15(4):591-605.

34. Heijens MRM, Elders LAM, Burdorf A. Prognostische factoren voor langdurig ziekteverzuim door klachten van het bewegingsapparaat onder verzuimers. TSG/Gezondheidsw. 2003; 81:142-7.

35. Dionne CE, Bourbonnais R, Fremont P, Rossignol M, Stock SR, Nouwen A, et al. Determinants of "return to work in good health" among workers with back pain who consult in primary care settings: a 2-year prospective study. Eur Spine J. 2007;16(5): 641-55.

36. Pransky G, Shaw W, Franche RL, Clarke A. Disability prevention and communication among workers, physicians, employers, and insurers-current models and opportunities for improvement. Disabil Rehabil. 2004;26(11):625-34.

37. Richtlijnen koninklijk nederlands genootschap voor fysiotherapie [homepage on the Internet]. Amersfoort: KNGF (2010). Available from: https://www.kngfrichtlijnen.nl/612/Richtlijnen.htm.

38. Schaafsma F, Schonstein E, Whelan KM, Ulvestad E, Kenny DT, Verbeek JH. Physical conditioning programs for improving work outcomes in workers with back pain. Cochrane Database Syst Rev. 2010;(1):CD001822.

39. Hayden JA, van Tulder MW, Malmivaara A, Koes BW. Exercise therapy for treatment of non-specific low back pain. Cochrane Database Syst Rev. 2005;(3):CD000335.

40. Lambeek LC, van Mechelen W, Knol DL, Loisel P, Anema JR. Randomised controlled trial of integrated care to reduce disability from chronic low back pain in working and private life. BMJ. 2010;340:c1035.

41. D'Agostino RB Jr. Propensity score methods for bias reduction in the comparison of a treatment to a non-randomized control group. Stat Med. 1998;17(19):2265-81. 